\title{
PENTINGNYA PENERAPAN K3 OLEH PERAWAT DALAM \\ MENINGKATKAN MUTU RUMAH SAKIT
}

JULIA RAHMA/191101040

emasurya123emasurya123@gmail.com

\section{LATAR BELAKANG}

Keselamatan pasien merupakan salah satu indikator kualitas pelayanan kesehatan. Meskipun data insiden keselamatan pasien di fasilitas pelayanan kesehatan tingkat pertama belum akurat di Indonesia, namun keselamatan pasien menjadi isu penting dalam peningkatan kualitas pelayanan. Keselamatan pasien yaitu menurut Emanuel (2008), yang menyatakan bahwa keselamatan pasien adalah disiplin ilmu di sektor perawatan kesehatan yang menerapkan metode ilmu keselamatan menuju tujuan mencapai sistem penyampaian layanan kesehatan yang dapat dipercaya. Keselamatan pasien juga merupakan atribut sistem perawatan kesehatan; Ini meminimalkan kejadian dan dampak, dan memaksimalkan pemulihan dari efek samping.

Keselamatan Pasien (KP) adalah suatu sistem dimana rumah sakit membuat asuhan pasien lebih aman, mencegah terjadinya cidera yang disebabkan oleh kesalahan akibat melaksanakan suatu tindakan atau tidak mengambiltindakan yang seharusnya diambil. Pada prinsipnyapelaksanaantujuhlangkahmenujukeselamatan pasien sesuai dengan standar Kementerian Kesehatan. Sistem manajemen keselamatan dan kesehatan kerja (SMK3) harus diterapkan di semua tempat kerja, termasuk rumah sakit yang mempunyai risiko tinggi terjadinya kecelakaan kerja dan penyakit akibat kerja. Kecelakaan kerja yang terjadi pada petugas kesehatan dipengaruhi oleh beberapa faktor.

Rumah sakit seharus memiliki sistem yang bebas dari kesalahan dan juga memiliki pelayanan kesehatan yang menjunjung tinggi hak hak pasien . Upaya meminimalisir terjadinya kesalahan medis atau yang terkait dengan aspek keselamatan pasien, maka manajemen rumah sakit perlu menciptakan sistem keselamatan pasien.

Kata Kunci : Penerapan K3 Perawat, Keselamatan Pasien, Rumah Sakit 


\section{METODE}

Metode yang digunakan dalam kajian ini adalah metode Litterature review dengan menganalisis, eksplorasi dan kajian bebas. Dimana hasil analisis ini bisa didapat sumber yaitu dengan membandingkan antar satu jurnal dengan jurnal yang lain. Kajian ini juga dapat dibuat dengan mencari berbagai sumber referensi lainnya baik itu jurnal maupun ebook yang berkenaan dengan dokumentasi asuhan keperawatan.

\section{HASIL}

Hasil yang diperoleh Perawat berperan penting dalam memastikan keselamatan pasien dengan memantau kondisi pasien untuk mencegah terjadinya insiden, memberikan pendidikan kesehatan, mendeteksi kesalahan dan nyaris cedera, serta melakukan tugas-tugas lain untuk memastikan pasien menerima perawatan yang berkualitas tinggi.

\section{PEMBAHASAN}

Rumah sakit rumah sakit mempunyai tujuan memberikan pelayanan kesehatan perorangan secara paripurna yaitu promotif, preventif, kuratif, dan rehabilitatif dalam rangka mewujudkan derajat kesehatan masyarakat yang setinggi-tingginya. Kenyataannya dalam pencapaian tujuan rumah sakit tersebut diatas terdapat beberapa faktor yang mempengaruhinya salah satunya keselamatan dan kesehatan SDM rumah sakit itu sendiri. SDM sangatlah dominan dalam pencapaian tujuan rumah sakit karena bagaimana mungkin pelayanan kesehatan diberikan secara maksimal oleh SDM rumah sakit dalam rangka mencapai derajat kesehatan masyarakat yang setinggi-tingginya kalau mereka sendiri dalam keadaan yang tidak selamat dan tidak sehat. Rumah sakit juga merupakan salah satu tempat kerja yang rentan akan bahaya kesehatan dan keselamatan bagi petugas, pasien, dan pengunjung. Hal ini senada dengan apa yang tertuang dalam Kepmenkes No.432/ MENKES/ SK/ IV/ 2007 tentang Pedoman Keselamatan dan Kesehatan Kerja di Rumah Sakit, dikatakan bahwa dalam kegiatan rumah sakit berpotensi menimbulkan bahaya fisik, kimia, biologi, ergonomik dan psikososial yang dapat membahayakan kesehatan dan keselamatan SDM RS, pasien, pengunjung / pengantar pasien, dan masyarakat sekitar RS (Kemenkes, 2007)1. Untuk itulah maka perlu adanya implementasi suatu sistem manajemen yang berfungsi dalam mencegah, mengatasi atapun menghilangkan bahaya bahaya tersebut. 
Keselamatan pasien yaitu menurut Emanuel (2008), yang menyatakan bahwa keselamatan pasien adalah disiplin ilmu di sektor perawatan kesehatan yang menerapkan metode ilmu keselamatan menuju tujuan mencapai sistem penyampaian layanan kesehatan yang dapat dipercaya. Keselamatan pasien juga merupakan atribut sistem perawatan kesehatan; Ini meminimalkan kejadian dan dampak, dan memaksimalkan pemulihan dari efek samping. Menurut Vincent (2008), keselamatan pasien didefinisikan sebagai penghindaran, pencegahan dan perbaikan dari hasil tindakan yang buruk atau injuri yang berasal dari proses perawatan kesehatan.

Menurut pedoman Manjamen Kesehatan dan Keselamatan Kerja ( K3 ) di rumah sakit, Depkes ( 2006 ), dalam undang - undang No 23 tahun 1992 tentang kesehatan pasal 23 dinyatakan bahwa upaya Kesehatan dan Keselamatan Kerja (K3) harus diselenggarakan disemua tempat kerja, khususnya tempat kerja yang mempunyai resiko bahaya kesehatan, mudah terjangkit penyakit atau mempunyai karyawan minimal 10 orang. Jika memperhatikan isi dari pasal tersebut, maka jelaslah bahwa rumah sakit termasuk kedalam kriteria tempat kerja dengan berbagai ancaman bahaya yang dapat menimbulkan dampak kesehatan, tidak hanya terhadap para pelaku langsung yang bekerja di rumah sakit, tapi juga terhadap pasien maupun pengunjung rumah sakit. Sehingga sudah seharusnyalah pihak pengelola rumah sakit menerapkan upaya Kesehatan dan Keselamatan Kerja ( K3 ) di Rumah Sakit.

\section{Indikator Keselamatan dan Kesehatan Kerja (K3) Menurut (Dessler:1997), indicator kesehatan karyawan terdiri dari :}

1. Keadaan dan Kondisi Karyawan Keadaan dan kondisi karyawan adalah keadaan yang dialami oleh karyawan pada saat bekerja yang mendukung aktifitas dalam bekerja.

2. Lingkungan kerja Lingkungan kerja adalah lingkungan yang lebih luas dari tempat kerja yang mendukung aktifitas karyawan dalam bekerja.

3. Perlindungan karyawan Perlindungan karyawan merupakan fasilitas yang diberikan untuk menunjang kesejahteraan karyawan.

4. Tempat kerja Adalah merupakan lokasi dimana para karyawan melaksanakan aktifitas kerjanya. 
5. Mesin dan peralatan Adalah bagian dari kegiatan operasional dalam proses produksi yang biasanya berupa alat-alat berat dan ringan.

\section{Faktor Pendorong Pen erapan K3 Di Rumah Sakit}

1. Komitmen Pimpinan Komitmen pimpinan yang dimaksud dalam penelitian ini adalah komitmen pimpinan RS X, komitmen pimpinan rumah sakit disini adalah suatu komitmen tertulis tentang dukungannya terhadap implementasi Keselamatan dan kesehatan kerja dilingkungan rumah sakit yang dipimpinnya. Komitmen ini berdasarkan standar dari Kemenkes No. 4327 tentang Pedoman Manajemen K3RS bahwa harus berupa surat keputusan pimpinan rumah sakit yang isinya tentang serangkaian program dan atau tindakan pencapaian tujuan dari K3RS. Jadi berdasarkan hal tersebut diatas maka dengan ditetapkannya kebijakan tentang K3 di rumah sakit ini oleh pimpinan RS maka pelaksana/pengelola keselamatan dan kesehatan kerja di rumah sakit mempunyai serangkaian acuan/standar dalam bertindak atau melaksanakan K3 ini yang diharapkan dapat berjalan dengan baik dan memenuhi standar yang ditetapkan. Pimpinan RS X telah menetapkan komitmen tersebut dalam bentuk SK Direktur RS X tentang pelaksanaan Keselamatan dan Kesehatan Kerja di lingkungan rumah sakit yang dipimpinya, SK ini menandai bahwa pelaksana/pengelola keselamatan dan kesehatan kerja di RS X mempunyai dasar hukumnya dan ada kejelasan arah dalam bertindak atau melaksanakan K3 di rumah sakit ini.

2. Disposisi / Komitmen Para Pelaksana (Implementors) Subarsono (2013) mengatakan bahwa disposisi (watak dan karakterisitik yang dimiliki oleh implementor, seperti komitmen, kejujuran dan sifat demokratis sangatlah penting dalam implementasi suatu kebijakan karena apabila implementor memiliki disposisi yang baik maka dia akan dapat menjalankan kebijakan dengan baik pula seperti apa yang diinginkan oleh pembuat kebijakan.3 Ketika implementor memiliki sikap atau perspektif yang berbeda dengan pembuat kebijakan maka proses implementasi kebijakan juga menjadi tidak efektif. Disposisi implementor dalam pelaksanaan kebijakan Kepmenkes No.1087/ MENKES/ SK/ VIII/ 2010 dalam rangka pemeliharaan Keselamatan dan Kesehatan Kerja di Rumah Sakit X menjadi faktor pendorong dalam keberhasilam dalam mengimplementasikan kebijakan ini karena implementor di RS X mempunyai komitmen yang cukup tinggi dalam menjalankan kebijakan K3 
sehingga arah menuju keberhasilan pencapaian tujuan kebijakan ini juga menjadi lebih terbuka lebar. Komitmen yang dimaksud adalah selalu menyelesaikan tugas yang diamanatkan, selalu mengikuti kegiatan yang berhubungan dengan $\mathrm{K} 3$, adanya rasa memiliki institusi.

Upaya Kesehatan dan Keselamatan Kerja harus diselenggarakan untuk mewujudkan produktivitas kerja yang optimal di semua tempat kerja, khususnya tempat yang mempunyai risiko bahaya kesehatan, mudah terjangkit penyakit. Sejalan dengan itu, maka rumah sakit termasuk ke dalam kriteria tempat kerja dengan berbagai potensi bahaya yang dapat menimbulkan dampak kesehatan (Kepmenkes, 2010).

Upaya keselamatan pasien harus dipahami dan didefinisikan dengan baik oleh seluruh pihak yang terlibat agar penerapan upaya keselamatan pasien dapat berjalan dengan baik dan mencapai tujuan yang diinginkan. Penerapan upaya keselamatan pasien untuk peningkatan mutu pelayanan kesehatan tidak hanya terkait dengan petugas atau sumber daya manusia yang terlibat. Namun penciptaan lingkungan yang aman dan terhindar dari hal-hal yang berpotensi membahayakan bagi pasien juga merupakan bentuk upaya keselamatan pasien (Ulrich \& Kear, 2014).

Upaya membangun keselamatan pasien memerlukan komitmen yang di pengaruhi oleh pengetahuan perawat. Pengetahuan perawat tentang keselamatan pasien menjamin mereka memiliki tanggung jawab untuk perbaikan proses. Perawat dan staf garis depan secara aktif terlibat dalam upaya untuk bersama-sama meningkatkan efisiensi dan meningkatkan kualitas pelayanan di rumah sakit (Needleman\& Hassmiller, 2009).

Ada enam sasaran keselamatan pasien di rumah sakit yaitu ketepatan identifikasi, peningkatan komunikasi efektif, peningkatan keamanan obat yang perlu diwaspadai, kepastian tepat lokasi, tepat prosedur, tepat pasien operasi, pengurangan resiko infeksi terkait pelayanann kesehatan pengurangan resiko pasien jatuh (Depkes, 2011). Keenam aspek tersebut sangat penting untuk dilaksanakan di setiap rumah sakit. Namun harus diakui kegiatan institusi rumah sakit dapat berjalan apabila ada pasien. Keselamatan pasien merupakan prioritas utama untuk dilaksanakan dan hal tersebut terkait dengan isu mutu dan citra perumahsakitan (Depkes, 2011). . Sasaran utama dari K3 ditujukan terhadap 
perawat, dengan melakukan segala daya upaya berupa pencegahan, pemeliharaan dan peningkatan kesehatan tenaga kerja, agar terhindar dari risiko buruk di dalam melakukan pekerjaan.

Ada 3 Faktor dalam Penerapan K3 di Rumah Sakit

1. Faktor motivasi dan persepsi dapat mempengaruhi kepatuhan perawat dalam pelaksanaan asuhan keperawatan yang sesuai dengan SOP. Perawat dengan persepsi baik memiliki kemungkinan lebih besar untuk patuh dibandingkan dengan perawat dengan persepsi kurang. Selain persepsi, sikap juga mempengaruhi perilaku perawat ditinjau dari segi faktor internal (Notoadmodjo, 2010). Seorang perawat dalam melaksanakan manajemen K3 harus memiliki sikap yang sesuai dengan nilai-nilai kesehatan dimana seluruh nilai positif yang ada dalam dirinya menjadi pendorong perilaku sehat dan menjadi upaya dalam meningkatkan kesehatan dan keselamatan selama bekerja.

2. Selain faktor internal, faktor eksternal juga sangat mempengaruhi perilaku perawat dalam penerapan manajemen K3 di rumah sakit. Salah satunya adalah masa kerja. Semakin lama masa kerja perawat maka pengalaman yang dimiliki juga semakin meningkat sehingga perilakunya dalam menjaga keselamatan dirinya juga menjadi lebih baik. Selain itu pengalaman juga dapat diperoleh dari berbagai sosialisasi maupun pelatihan tentang K3 yang dilakukan oleh pihak rumah sakit..

3. Faktor selanjutnya yang ikut berperan dalam perubahan perilaku perawat yaitu tersedianya fasilitas yang mendukung sesuai dengan standar yang telah ditentukan. Hal ini sejalan dengan penelitian Tukatman, Sulistiawati, Purwaningsih dan Nursalam (2015) yang menyebutkan bahwa faktor enabling (fasilitas keamanan dan keselamatan, hukum/aturan) pada perawat berpengaruh terhadap K3 pada perawat dalam penanganan pasien. Nilai yang paling tinggi pada faktor enabling berada pada komponen hukum/aturan, artinya secara umum perilaku seseorang dipengaruhi oleh aturan yang ada di lingkungannya. Selain beberapa faktor diatas, budaya organisasi juga berpengaruh terhadap perilaku perawat dalam melaksanakan keselamatan, dimana budaya organisasi yang baik akan mendorong perawat untuk bekerja sesuai dengan prosedur yang telah ditetentukan (Notoadmodjo, 2010). Hal ini sejalan dengan penelitian Mulyatiningsih (2013) tentang determinan perilaku perawat dalam melaksanakan keselamatan pasien yang menunjukkan adanya hubungan yang 
signifikan antara budaya organisasi dengan perilaku perawat dalam menjaga keselamatan.

\section{PENUTUP}

Perawat harus menyadari perannya sehingga harus berpartisipasi aktif dalam mewujudkan keselamatan pasien rumah sakit. Perawat harus memahami tentang apa yang dimaksud dengan keselamatan pasien rumah sakit (KPRS) serta dalam pelaksanan pelayanan harus mengetahui enam sasaran keselamatan pasien yaitu: ketepatan identifikasi pasien, peningkatan komunikasi efektif, peningkatan keamanan obat yang perlu diwaspadai, kepastian tepat lokasi, tepat prosedur, tepat pasien operasi, pengurangan resiko infeksi terkait pelayanan kesehatan, pengurangan resiko jatuh sehingga perawat dapat melaksanakan asuhan keperawatan kepada pasien secara aman.

Selain itu, untuk mewujudkan patient safety dibutuhkan upaya dan kerjasama berbagai pihak. Patient safety merupakan upaya dari seluruh komponen sarana pelayanan kesehatan, dan perawat memegang peran kunci untuk mencapainya.

\section{REFERENSI}

Butar-butar, J., \& Simamora, R. H. (2016). Hubungan Mutu Pelayanan Keperawatan dengan Tingkat Kepuasan Pasien Rawat Inap di RSUD Pandan Kabupaten Tapanuli Tengah. Jurnal Ners Indonesia, 6(1), 50-63.

Cahyono, S, J.(2008). Keselamatan pasien dalam praktik kedokteran. Yogyakarta: KANSIUS

Firawati., Pabuty. A., \& Putra, A. S. (2012). Pelaksanaan Program Keselamatan Pasien di RSUD Solok. Jurnal Kesehatan Masyarakat, 6 (2), 73-79.

Harus , B.D . Sutriningsih, A . ( 2015 ) . Pengetahuan Perawat Tentang Keselamata Pasien dengan Pelaksanaan Prosedur Keselamatan Pasien Rumah Sakit ( KPRS ) di Rumah Sakit Panti Waluya Sawahan Malang . Jurnal CARE . Vol. 3

Hasibuan , R . ( 2017 ) . Pengaruh Kesehatan Keselamatan Kerja, Pelatihan dan Kerja Tim Terhadap Kinerja Tenaga Medis di Rumah Sakit Budi Kemuliaan Batam . DIMENSI, ISSN: 2085-9996 . VOL. 6. 
Ilyas, M. M. (2019). FAKTOR-FAKTOR YANG MEMPENGARUHI IMPLEMENTASI KEPMENKES NO.1087/MENKES/SK/VIII/2010 TENTANG KESELAMATAN DAN KESEHATAN KERJA DI RUMAH SAKIT. Jurnal Pemerintahan dan Politik, 2(1).

Insani, T. H. N., \& Sundari. S. (2018). Analisis Pelaksanaan Keselamatan Pasien Oleh Perawat. Journal of Health Studies, 2 (1), 84-95.

Ismaniar, H. (2015). Keselamatan Pasien di Rumah Sakit. Yogyakarta : Deepublish

Nazirah , R . Yuswardi . (2017) . Perilaku Perawat dalam Penerapan Manajemen Kesehatan dan Keselamatan Kerja (K3) di Aceh . Idea Nursing Journal . Vol. VIII

Nurhidayanti , D . (2017). Pengaruh Pelaksanaan Keselamatan dan Kesehatan Kerja (K3) Terhadap Kepuasan Kerja Perawat (Studi Kasus Rumah Sakit Umum Daerah (RSUD) Arifin Achmad Pekanbaru) . JOM FISIP Vol. 4

Rahmawati , R . (2017) . Gambaran Penerapan Program Kesehatan dan Keselamatan Kerja Rumah Sakit ( K3RS ) pada Perawat dI RSUD TUGUREJO SEMARANG . PROPOSAL SKRIPSI . DEPARTEMEN ILMU KEPERAWATAN FAKULTAS KEDOKTERAN UNIVERSITAS DIPONEGORO

Salmawati , L . Sumarni . DW \& Soebijanto . (2015) . Hubungan Penerapan Sistem Manajemen Keselamatan dan Kesehatan Kerja dengan Keselamatan Kerja dan Stres Kerja pada Perawat di Rumah Sakit Umum Anutapura Palu . Jurnal Manajemen Pelayanan Kesehatan, Vol. 18.

Sukesi , I . Soeharto, S . Ahsan . (2015) . Analisis Faktor yang Berhubungan dengan Kinerja Perawat Melaksanakan Keselamtan Pasien . e-journal.umm. Volume 6

Simamora, R. H. (2018). Buku ajar keselamatan pasien melalui timbang terima pasien berbasis komunikasi efektif: SBAR. Medan: USUpress.

Simamora, R. H. (2019). Buku ajar pelaksanaan identifikasi pasien. Uwais Inspirasi Indonesia

Widiasari., Handiyani. H., \& Novieastari. (2019). Kepuasan Pasien Terhadap Penerapan Keselamatan Pasien di Rumah Sakit. Jurnal Keperawatan Indonesia, 22 (1), 43-52. 
